\title{
THE EFFECT OF 5K2S IMPLEMENTATION TO THE OPPORTUNITIES OF INCREASING PRODUCTIVITY AND WORKPLACE IMPROVEMENT IN PT ANDESEN JAYA PLASTIK
}

\author{
Rachmatullah $^{1}$; Tota Pirdo Kasih ${ }^{2}$; Hardi Humiras Purba ${ }^{3}$ \\ ${ }^{1}$ Teknik Industri Sekolah Tinggi Teknologi Texmaco \\ Desa Kiarapayung Kawasan Industri Citarum Klari Karawang Timur, Jawa Barat. \\ rachmatullah_447@yahoo.com

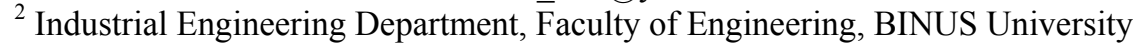 \\ Jl. KH. Syahdan no. 9, Palmerah, Jakarta Barat, Indonesia \\ tkasih@binus.edu \\ ${ }^{3}$ Program Pasca Sarjana, Magister Teknik Industri, Universitas Mercu Buana. \\ Jl. Meruya Selatan, Kebun Jeruk - Jakarta Barat
}

\begin{abstract}
The success of Japanese companies in improving productivity is because they have a culture and a high work ethic to the application of KAIZEN management system. One such application is the Cultural 5S (Seiri, Seiton, Seiso, Seiketsu, Shitsuke). In the Astra group, 5S is known as 5K2S (Order, neatness, cleanliness, sustainability Discipline, Safety, and Service). This study aims to assess the success of the application of the system 5K2S of PT. Andesen Jaya Plastik relating to opportunities for productivity. The method used is quantitative method with a descriptive study. The type of data used is primary and secondary data. While the techniques used in collecting the data are interviews, questionnaires, and literature studies. The number of respondents was 31 employees. Analysis of the data used is descriptive and multiple linear regression analysis. The real success rate reachs $82.24 \%$ at the stage of familiarization (effective) and they have not yet advanced to the next stage (prevention). The response of employees is between the Agree and Strongly Agree that is 4.11 point. The correlation between 5K2S to the opportunity of significant Productivity Improvement is Seiri/Order, Seiso/neatness, and Seiketsu/Sustainability.
\end{abstract}

Keywords: productivity, 5k2s, kaizen

\begin{abstract}
ABSTRAK
Keberhasilan perusahaan-perusahaan Jepang dalam meningkatkan produktivitas adalah karena mereka mempunyai budaya dan etos kerja yang tinggi terhadap penerapan sistim manajemen KAIZEN. Salah satu penerapan tersebut adalah Budaya 5S (Seiri, Seiton, Seiso, Seiketsu, Shitsuke). Di grup Astra, 5S ini dikenal dengan istilah 5K2S (Ketertiban, Kerapihan, Kebersihan, Kelestarian Kedisiplinan, Safety, dan Service). Penelitian ini bertujuan untuk mengetahui tingkat keberhasilan penerapan sistim 5K2S di PT. Andesen Jaya Plastik yang berkaitan dengan peluang terhadap produktivitas. Metode yang digunakan adalah metode kuantitatif dengan penelitian deskriptif. Jenis data yang digunakan adalah data primer dan sekunder. Sedangkan teknik yang digunakan dalam mengumpulkan data adalah wawancara, kuesioner, dan studi literatur. jumlah responden adalah 31 karyawan. Analisis data yang digunakan adalah deskriptif dan analisis regresi linier berganda. Tingkat keberhasilan nyata mencapai 82,24\% yaitu pada tahap pembudayaan (efektif) belum ke tahap lanjutan (pencegahan). Respon karyawan berada antara Setuju dan Sangat Setuju yaitu 4,11 point. Uji korelasi antara 5K2S terhadap peluang Peningkatan Produktivitas yang berpengaruh secara signifikan adalah Seiri/Ketertiban, Seiso/Kerapihan, dan Seiketsu/Kelestarian.
\end{abstract}

Kata kunci: Produktivitas, 5K2S dan Kaizen. 


\section{PENDAHULUAN}

Pemeliharaan dan penataan tempat kerja merupakan tema yang menarik bagi perusahaan yang ingin meningkatkan kinerja dan produktivitas. Industri-industri yang mengimplementasikan $5 \mathrm{~S}$ sebagai salah satu sistimnya dengan baik maka dapat lebih efektif dan effisien dalam berproses produksi. Berapa banyak perusahaan yang telah mencoba melaksanakan budaya $5 \mathrm{~S}$ tetapi mendapatkan kesulitan untuk tetap mempertahaannya. Untuk itu seharusnya disiplin 5S yang mendasar, semestinya harus diikuti oleh semua karyawan terhadap pemeliharaan tempat kerja yang harus menjadi langkah pertama yang diambil oleh manajemen untuk memperbaiki operasi pabrik. Terkadang manajemen terlalu banyak mempergunakan waktu untuk menghitung-hitung dan menulis berbagai laporan. Akibatnya, kegiatan mendasar $5 \mathrm{~S}$ yang seharusnya terjadi di tempat kerja sering kali terabaikan.

Cara mudah untuk melaksanakan dan menilai sikap kerja suatu perusahaan terhadap kegiatan 5S adalah dengan Genba (Melihat dan menganalisis langsung di tempat kerja). Genba dilakukan dengan berjalan mengelilingi pabrik dan mengamati pelaksanaan pemeliharaan $5 \mathrm{~S}$ di tempat kerja secara langsung. Sering kali kondisi perusahaan, justru lebih tergambar melalui penglihatan dan pengamatan pemeliharaan tempat kerja, dibandingkan dengan membaca laporan, apalagi yang dilihat hanya laporan keuangan saja. Penerapan $5 \mathrm{~S}$ terlihat pada kegiatan perbaikan dan kebiasaan penyimpanan alat-alat, kemudian penanganan sampah dan bahan sisa dari proses dan mesin, mesin kerja yang terlihat tertata rapih dan tertib, petunjuk operasi yang jelas, lantai pabrik yang bersih, mesin yang bersih, peralatan pabrik yang tersimpan rapih dan seterusnya.

Praktek pemeliharaan tempat kerja adalah cerminan sikap sehari-hari dari manajemen terhadap pekerjaan dan kegiatan kerja. Artinya pemeliharaan tempat kerja sangat erat kaitannya dengan aspek-aspek penting manajemen termasuk moral karyawan, hubungan manajemen karyawan, dan penerapan perbaikan lingkungan kerja. Untuk itu perlu ditingkatkan tentang hubungan antara pemeliharaan tempat kerja dengan upaya peningkatan produktivitas, seringnya gangguan mesin, pola aliran produksi, tingkat persediaan, jumlah saran-saran perbaikan, tingkat absen dan lainnya. Hanya dengan memahami hubungan inilah maka dapat ditetapkan tindakan apakah yang perlu dilakukan untuk meningkatkan operasi produksi, dengan demikian pemeliharaan tempat kerja adalah tugas semua orang yang terlibat didalam kepentingan tersebut. Oleh karena itu dalam pengembangan lingkungan bisnis, manajemen perlu mengubah paradigma mereka agar sikap dan tindakan mereka dalam menjalankan bisnis menjadi efektif (Mulyadi, 1998).

Tentunya hanya perusahaan yang mampu memiliki produktivitas yang tinggi, dengan komitmen untuk mengurangi atau bahkan menghilangkan pemborosan-pemborosan sepanjang jalur produksinya, yang akan memenangkan persaingan bisnis tersebut (Cho, 2001). Tujuan dari penelitian adalah untuk menganalisis pengaruh implementasi $5 \mathrm{~K} 2 \mathrm{~S}$ terhadap besaran kontribusi dan upaya peningkatan dan tingkat keberhasilan produktivitas dalam lingkungan kerja termasuk tingkat pemahaman karyawan terhadap sistim tersebut. Melalui Genba (Melihat dan menganalisis langsung di tempat kerja), wawancara, penyebaran kuesioner dan olah data dengan menghitung harga korelasi sesuai rumus Pearson Product Moment (Y. Wibisono, 2009), Uji reliabilitas untuk mengetahui tingkat kepercayaan terhadap alat pengumpul data, (Arikunto \& Suharsimi, 2006) dan Uji hipotesis menggunakan Korelasi Product Moment, (Sugiyono, 2002). 


\section{METODE}

Untuk mengetahui sejauh mana korelasi antara implementasi $5 \mathrm{~K} 2 \mathrm{~S}$ terhadap upaya peningkatan produktivitas di PT.Andesen Jaya Plastik adalah dengan mengolah data kuesioner yg telah disebarkan kepada karyawan secara sampling dengan rumusan sebagai berikut: Untuk data dari 5 variabel terdiri dari X1 (Ketertiban), X2 (Kerapihan), X3 (Kebersihan), X4 (Kelestarian), dan X5 (Kedisiplinan) sedangkan 2S (safety dan Service) tidak diikutkan karena dimasukkan dalam kegiatan K3. (Keselamatan Dan Kesehatan Kerja) yang mempunyai sistim pelaporan tersendiri. Upaya peningkatan produktivitas sebagai variabel $\mathrm{Y}$ bersifat terikat, terdiri dari 5 pertanyaan sebagai unsur upaya peningkatan produktivitas. Analisis untuk menguji kecukupan data dari kuesioner dengan menggunakan rumus sebagai berikut (Sarwono dan Martadiredja, 2008):

$$
N=\frac{Z^{2} p q}{e^{2}}
$$

$\mathrm{N}=$ Jumlah Pengamatan yang seharusnya dilakukan.

$\mathrm{Z}=\mathrm{Z}$ (tabel normal) yang berhubungan dengan tingkat ketelitian.

$\mathrm{p}=$ Persentase Kuesioner Layak.

dengan $\mathrm{p}=$ (total kuesioner yang disebar-total kuesioner cacat)/total kuesioner yang disebar

$\mathrm{q}=$ Persentase Kuesioner cacat dengan $\mathrm{q}=1-\mathrm{p}$.

$\mathrm{e}=$ Persentase kelonggaran ketelitian.

Untuk menindak lanjuti proses pengolahan data agar dapat menjelaskan terhadap korelasi tersebut adalah dengan langkah-langkah sebagai berikut:

Langkah 1. Menghitung harga korelasi dengan rumus Pearson Product Moment (Y.Wibisono, 2009)

Nilai koefisien korelasinya:

$$
r=\frac{N\left(\sum X Y\right)-\left(\sum X \sum Y\right)}{\sqrt{\left[N \Sigma X^{2}-(\Sigma X)^{2}\right]\left[N \Sigma Y^{2}-(\Sigma Y)^{2}\right]}}
$$

Langkah 2: Menghitung harga $t_{\text {hitung }}$ dengan rumus : $t_{\text {hitung }}$ (Umar Husein, 1997):

$$
t_{\text {hitung }}=\frac{r \sqrt{n-2}}{\sqrt{1-r^{2}}}
$$

Langkah 3: Mencari $\mathrm{r}_{\text {tabel }}$ apabila diketahui signifikan $\alpha=0.05$ dan derajad kebebasan $(\mathrm{dk})=\mathrm{N}-2$, dengan uji satu pihak, kemudian dicari nilai tabel tersebut.

Langkah 4: Membuat keputusan dengan membandingkan $t_{\text {hitung }}$ dengan $t_{\text {tabel }}$ kaidah keputusan: Jika $t_{\text {hitung }}>t_{\text {tabel }}$ berarti valid dan, $t_{\text {hitung }}<t_{\text {tabel }}$ berarti tidak valid.

\section{Analisis Untuk Mengetahui Reliabilitas Data}

Uji reliabilitas dilakukan untuk mengetahui tingkat kepercayaan terhadap alat pengumpul data. Rumus yang digunakan adalah (Suharsimi A, 2002): 


$$
\begin{aligned}
\mathrm{r}_{11}= & \left.\frac{\mathrm{k}}{\mathrm{k}-1}\right] \quad\left[1-\frac{\zeta \sigma^{2} \mathrm{~b}}{\sigma_{1}{ }^{2}}\right] \\
& =\text { reliabilitas instrumen } \\
\mathrm{r}_{11} & =\text { banyaknya butir pertanyaan atau banyaknya soal } \\
\mathrm{k} \sigma^{2} & =\text { jumlah varians butir } \\
\sum_{1}^{2} & =\text { varians total }
\end{aligned}
$$

Secara empiris, diberikan ketentuan bahwa $\alpha<0.6$ mengindikasikan reliabilitas yang tidak memuaskan. Dengan kata lain, reliabelitas konsisten dapat diterima jika $\alpha \geq 0$.6. Perhitungan analisis data khusus untuk menghitung korelasi dan regresi ganda menggunakan program statistik SPSS versi 22. Untuk penetapan kriteria yang menunjukan kuat atau lemahnya korelasi adalah (Sarwono, 2006):

(1) Angka korelasi berkisar antara $0 \mathrm{~s} / \mathrm{d}$ 1. (2) Besar kecil angka korelasi menentukan kuat atau lemahnya hubungan kedua variabel. Patokan angkanya adalah sebagai berikut:

$$
\begin{array}{cll}
0-0.25 & : & \text { Korelasi sangat lemah (dianggap tidak ada) } \\
>0.25-0.50 & : \text { Korelasi cukup } \\
>0.50-0.75 & : \text { Korelasi kuat } \\
>0.75-1 & : \text { Korelasi sangat kuat. }
\end{array}
$$

Korelasi dapat positif (+) dan negatif (-). Korelasi positif menunjukan arah yang sama pada hubungan antar variabel, artinya, jika variabel 1 besar, maka variabel 2 akan semakin besar pula. Sebaliknya korelasi negatif menunjukkan arah yang berlawanan. Signifikan hubungan dua variable dapat dianalisis dengan ketentuan sebagai berikut: (1) Jika probabilitas $<0.05$ maka hubungan kedua variable signifikan. (2) Jika probabilitas $>0.05$ maka hubungan kedua variable tidak signifikan.

\section{Uji Hipotesis}

Uji hipotesis menggunakan Korelasi Product Moment sementara untuk memprediksi nilai variabel produktivitas berdasarkan nilai variabel budaya $5 \mathrm{~K} 2 \mathrm{~S}$ dilakukan analisis regresi. Formulasi atau rumus yang digunakan adalah rumus korelasi, (Lihat rumus korelasi di atas) dan Rumus uji signifikan (t) (Sugiyono, 2002).

$$
t=\frac{r \sqrt{n-2}}{\sqrt{1-r^{2}}}
$$

$\mathrm{r} \quad$ : Nilai/skor korelasi implementasi 5K2S dan produktivitas

$\mathrm{n}$ : Jumlah responden.

$\mathrm{t}$ : Nilai yang menunjukan signifikasi atau tidak ada hubungan antara $\mathrm{x}$ dan $\mathrm{y}$.

Dari langkah-langkah perumusan tersebut, selanjutnya dianalisis kondisi yang terjadi sesuai dengan hasil yang tersaji dalam hasil olah data tersebut. Dengan demikian akan tergambar secara jelas apa yang menjadi hasil penelitian tersebut, apakah dari kelima variabel tersebut mempunyai korelasi yang sigifikan atau sebaliknya. Dengan demikian, tindak lanjut dapat dilakukan untuk mengatasi kondisi tersebut, yaitu kendala yang masih berlanjut dalam inspeksi bulanan tentang temuan $5 \mathrm{~K}$ tersebut. 


\section{HASIL DAN PEMBAHASAN}

Rata-rata jawaban $(4.06+4.08+4.19+4.03+4.20+4.14) / 6=4.11$ point. Artinya jawaban dari masing-masing butir pertanyaan di respon positif, berada diantara Setuju dan Sangat Setuju (Gambar 1). Capaian Budaya 5K2S dibagi dalam 5 variable bebas, yaitu variabel terdiri dari lima butir pertanyaan, skor ideal adalah 5 × 5 × $31=775$ (5 nilai tertinggi, 5 jumlah butir pertanyaan, 31 jumlah responden). Sedang total score adalah jumlah nilai Total.

Tabel 1 Sebaran Data Responden Terhadap Semua Pertanyaan

\begin{tabular}{|c|c|c|c|c|c|c|c|c|c|c|c|c|c|c|}
\hline \multirow{2}{*}{\multicolumn{2}{|c|}{ Variabel }} & \multicolumn{5}{|c|}{ Frekuensi } & \multicolumn{5}{|c|}{ Percentage(\%) } & \multirow{3}{*}{\begin{tabular}{|c|} 
Total \\
134 \\
\end{tabular}} & \multirow{2}{*}{\multicolumn{2}{|c|}{ Rata-rata }} \\
\hline & & 1 & 2 & 3 & 4 & 5 & 1 & 2 & 3 & \begin{tabular}{|l|}
4 \\
\end{tabular} & 5 & & & \\
\hline \multirow{5}{*}{$\underbrace{\text { Seiri }}_{\text {KETERTIBAN }}$} & P1 & 0 & 0 & 1 & 19 & 11 & $0,00 \%$ & $0,00 \%$ & $3,23 \%$ & $61,29 \%$ & $35,48 \%$ & & 4,32 & \multirow{5}{*}{4,06} \\
\hline & P2 & 2 & 3 & 1 & 18 & 7 & $6,45 \%$ & $9,68 \%$ & $3,23 \%$ & $58,06 \%$ & $22,58 \%$ & 118 & 3,81 & \\
\hline & P3 & 0 & 0 & 3 & 22 & 6 & $0,00 \%$ & $0,00 \%$ & $9,68 \%$ & $70,97 \%$ & $19,35 \%$ & 127 & 4,10 & \\
\hline & P4 & 0 & 0 & 4 & 19 & 8 & $0,00 \%$ & $0,00 \%$ & $12,90 \%$ & $61,29 \%$ & $25,81 \%$ & 128 & 4,13 & \\
\hline & P5 & 0 & 3 & 1 & 21 & 6 & $0,00 \%$ & $9,68 \%$ & $3,23 \%$ & $67,74 \%$ & $19,35 \%$ & 123 & 3,97 & \\
\hline \multirow{5}{*}{$\frac{\text { Seiton }}{\text { KERAPIHAN }}$} & P6 & 0 & 0 & 0 & 22 & 9 & $0,00 \%$ & $0,00 \%$ & $0,00 \%$ & $70,97 \%$ & $29,03 \%$ & 133 & 4,29 & \multirow{5}{*}{4,08} \\
\hline & P7 & 0 & 1 & 4 & 21 & 5 & $0,00 \%$ & $3,23 \%$ & $12,90 \%$ & $67,74 \%$ & $16,13 \%$ & 123 & 3,97 & \\
\hline & P8 & 0 & 0 & 2 & 23 & 6 & $0,00 \%$ & $0,00 \%$ & $6,45 \%$ & $74,19 \%$ & $19,35 \%$ & 128 & 4,13 & \\
\hline & P9 & 0 & 2 & 6 & 17 & 6 & $0,00 \%$ & $6,45 \%$ & $19,35 \%$ & $54,84 \%$ & $19,35 \%$ & 120 & 3,87 & \\
\hline & P10 & 0 & 1 & 1 & 21 & 8 & $0,00 \%$ & $3,23 \%$ & $3,23 \%$ & $67,74 \%$ & $25,81 \%$ & 129 & 4,16 & \\
\hline \multirow{5}{*}{$\underbrace{\text { Seiso }}_{\text {KEBERSIHAN }}$} & P11 & 1 & 0 & 1 & 16 & 13 & $3,23 \%$ & $0,00 \%$ & $3,23 \%$ & $51,61 \%$ & $41,94 \%$ & 133 & 4,29 & \multirow{5}{*}{4,19} \\
\hline & P12 & 0 & 0 & 3 & 20 & 8 & $0,00 \%$ & $0,00 \%$ & $9,68 \%$ & $64,52 \%$ & $25,81 \%$ & 129 & 4,16 & \\
\hline & P13 & 0 & 0 & 2 & 21 & 8 & $0,00 \%$ & $0,00 \%$ & $6,45 \%$ & $67,74 \%$ & $25,81 \%$ & 130 & 4,19 & \\
\hline & P14 & 0 & 1 & 2 & 18 & 10 & $0,00 \%$ & $3,23 \%$ & $6,45 \%$ & $58,06 \%$ & $32,26 \%$ & 130 & 4,19 & \\
\hline & P15 & 0 & 1 & 3 & 19 & 8 & $0,00 \%$ & $3,23 \%$ & $9,68 \%$ & $61,29 \%$ & $25,81 \%$ & 127 & 4,10 & \\
\hline \multirow{5}{*}{$\underset{\text { KELESTARIAN }}{\text { Seiketsu }}$} & P16 & 0 & 0 & 1 & 25 & 5 & $0,00 \%$ & $0,00 \%$ & $3,23 \%$ & $80,65 \%$ & $16,13 \%$ & 128 & 4,13 & \multirow{5}{*}{4,03} \\
\hline & P17 & 0 & 1 & 2 & 23 & 5 & $0,00 \%$ & $3,23 \%$ & $6,45 \%$ & $74,19 \%$ & $16,13 \%$ & 125 & 4,03 & \\
\hline & P18 & 2 & 1 & 2 & 22 & 4 & $6,45 \%$ & $3,23 \%$ & $6,45 \%$ & $70,97 \%$ & $12,90 \%$ & 118 & 3,81 & \\
\hline & P19 & 0 & 1 & 6 & 22 & 2 & $0,00 \%$ & $3,23 \%$ & $19,35 \%$ & $70,97 \%$ & $6,45 \%$ & 118 & 3,81 & \\
\hline & P20 & 0 & 0 & 0 & 20 & 11 & $0,00 \%$ & $0,00 \%$ & $0,00 \%$ & $64,52 \%$ & $35,48 \%$ & 135 & 4,35 & \\
\hline \multirow{5}{*}{$\underbrace{\text { Sitsuke }}_{\text {KEDISPLINAN }}$} & P21 & 0 & 0 & 1 & 23 & 7 & $0,00 \%$ & $0,00 \%$ & $3,23 \%$ & $74,19 \%$ & $22,58 \%$ & 130 & 4,19 & \multirow{5}{*}{4,20} \\
\hline & P22 & 0 & 0 & 1 & 23 & 7 & $0,00 \%$ & $0,00 \%$ & $3,23 \%$ & $74,19 \%$ & $22,58 \%$ & 130 & 4,19 & \\
\hline & P23 & 0 & 0 & 0 & 24 & 7 & $0,00 \%$ & $0,00 \%$ & $0,00 \%$ & $77,42 \%$ & $22,58 \%$ & 131 & 4,23 & \\
\hline & P24 & 0 & 0 & 1 & 23 & 7 & $0,00 \%$ & $0,00 \%$ & $3,23 \%$ & $74,19 \%$ & $22,58 \%$ & 130 & 4,19 & \\
\hline & P25 & 0 & 0 & 0 & 25 & 6 & $0,00 \%$ & $0,00 \%$ & $0,00 \%$ & $80,65 \%$ & $19,35 \%$ & 130 & 4,19 & \\
\hline \multirow{5}{*}{ Produktivitas } & P26 & 0 & 0 & 0 & 24 & 7 & $0,00 \%$ & $0,00 \%$ & $0,00 \%$ & $77,42 \%$ & $22,58 \%$ & 131 & 4,23 & \multirow{5}{*}{4,14} \\
\hline & P27 & 0 & 0 & 2 & 21 & 8 & $0,00 \%$ & $0,00 \%$ & $6,45 \%$ & $67,74 \%$ & $25,81 \%$ & 130 & 4,19 & \\
\hline & P28 & 0 & 2 & 6 & 18 & 5 & $0,00 \%$ & $6,45 \%$ & $19,35 \%$ & $58,06 \%$ & $16,13 \%$ & 119 & 3,84 & \\
\hline & P29 & 0 & 0 & 0 & 24 & 7 & $0,00 \%$ & $0,00 \%$ & $0,00 \%$ & $77,42 \%$ & $22,58 \%$ & 131 & 4,23 & \\
\hline & P30 & 0 & 0 & 1 & 22 & 8 & $0,00 \%$ & $0,00 \%$ & $3,23 \%$ & $70,97 \%$ & $25,81 \%$ & 131 & 4,23 & \\
\hline
\end{tabular}

\begin{tabular}{|c|c|c|c|c|c|}
\hline 㘧 & 约 & 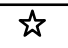 & $\underline{\Delta}$ & $\sum(4.11)$ & $\hbar$ \\
\hline \multirow[t]{2}{*}{0} & 1 & 2 & 3 & 4 & 5 \\
\hline & $\begin{array}{c}\text { SANGAT } \\
\text { TIDAK } \\
\text { SETUJU }\end{array}$ & $\begin{array}{l}\text { TIDAK } \\
\text { SETUJU }\end{array}$ & $\begin{array}{l}\text { RAGU- } \\
\text { RAGU }\end{array}$ & SETUJu & $\begin{array}{l}\text { SANGAT } \\
\text { SETUJU }\end{array}$ \\
\hline
\end{tabular}

Gambar 1 Rata-Rata Hasil Respon Pertanyaan Kuesioner

Tabel 2 Pencapaian 5K2S seksi Produksi

\begin{tabular}{|c|c|c|c|}
\hline No & Total Score & Variabel 5K2S & $\begin{array}{c}\text { Capaian } \\
(\%)\end{array}$ \\
\hline 1 & 630 & Seiri (Ketertiban) 630/775 x 100\% & 81.29 \\
\hline 2 & 633 & Seiton (Kerapihan) 633/775 x 100\% & 81.67 \\
\hline 3 & 649 & Seiso (Kebersihan) 649/775 x 100\% & 83.74 \\
\hline 4 & 624 & Seiketsu (kelestarian) $624 / 775 \times 100 \%$ & 80.51 \\
\hline 5 & 651 & Shitsuke (kedisiplinan) $651 / 775 \times 100 \%$ & 84.00 \\
\hline \multicolumn{3}{|c|}{ Budaya 5K2S PT. X } & 82.24 \\
\hline
\end{tabular}




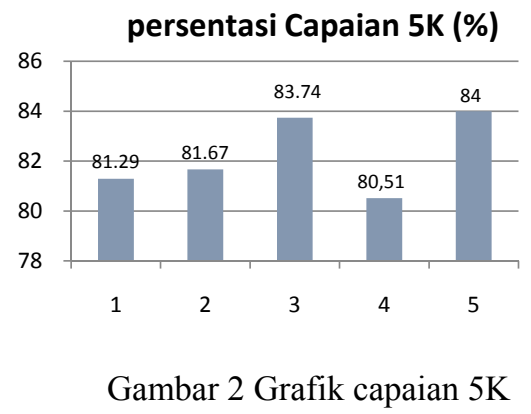

Melihat data deskriptif di atas dapat diketahui bahwa implementasi budaya 5K2S yang dilakukan PT. Andesen Jaya Plastik secara keseluruhan adalah $82.24 \%$, artinya secara umum 5K2S sudah dilaksanakan dengan baik, tapi masih perlu peningkatan, bila dievaluasi dengan skor Hirano (2002) sudah mencapai kategori di atas rata-rata atau sudah melewati tahap I (Aktif) dan tahap II (Pembudayaan) maka harus ditetapkan target yang lebih tinggi lagi yaitu menuju 5K2S tahap ke III (Pencegahan). Setelah mendapatkan data hasil survei, selanjutnya diadakan uji validitas dan reliabilitas dengan tujuan untuk menguji apakah data tersebut sudah valid dan reliabel.

Tabel 3 Hasil Hitung Uji Validitas dan Reabilitas

\begin{tabular}{|c|c|c|c|c|c|c|}
\hline \multirow{2}{*}{$\begin{array}{c}\text { Varia } \\
\text { bel }\end{array}$} & \multicolumn{3}{|c|}{ VALBITAS } & \multicolumn{3}{|c|}{ RELuAlitus } \\
\hline & rhinas & $\begin{array}{l}\text { rabed } \\
\text { (X) }\end{array}$ & Keterangan & 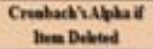 & CAsarvala & Keternatan \\
\hline$n$ & 0,434 & 0.361 & VALI & Q.xy9 & 0.70 & Relistal \\
\hline 72 & 0.650 & 0,361 & FAL & 0.859 & 0.70 & Rolashal \\
\hline$p$ & 0,44 & 0.301 & FALT & 0.536 & 0.00 & Retistal \\
\hline $\mathbf{N}$ & 0,591 & 0,301 & VALD & 0,01 & $a 0$ & Ratiatal \\
\hline क & $0,4 \pi$ & 0.361 & FALI & 0.81 & 0,00 & Rolitulat \\
\hline $\mathrm{PH}$ & 0,630 & 0.361 & VALI & 0.830 & 0,0 & Roliabal \\
\hline$n$ & 0.359 & 0.301 & Fand & 0.850 & 0.70 & Relliabed \\
\hline $\mathrm{nn}$ & 0,731 & 0.361 & TALD & 0.823 & 0,0 & Relialal \\
\hline 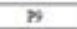 & 0.055 & 0.361 & Full & 0,836 & 0.70 & Reliabed \\
\hline pro & 0,476 & 0.201 & FALI & 0.035 & 0,0 & Ralisatal \\
\hline nit & 0,599 & 0,361 & ₹ED & $0 \times 31$ & 0,0 & Relisistal \\
\hline म2 & 0.611 & $0,0,6 !$ & VALD & 0,255 & 0,00 & Relabtal \\
\hline कis & 0.458 & 0.361 & VALID & 0,351 & 0,70 & Relabial \\
\hline nit & 0.597 & 0.061 & VMD & 0,826 & 0,70 & Robalal \\
\hline P15 & 0.915 & $0.36 !$ & VALI & 0.251 & 0,70 & Relister \\
\hline P16 & 0.610 & 0.361 & हया & 0.827 & 0.00 & Roliablat \\
\hline F17 & 0.065 & 0.361 & VALI & 0.323 & 0,20 & Relisber \\
\hline P18 & 0,726 & 0.361 & FALD & 0,243 & 0,00 & Reloblat \\
\hline P19 & 0.034 & 0.361 & Vum & 0.838 & 0,70 & Roliabled \\
\hline$p 20$ & 0,456 & 0.361 & Fa孟 & 0.827 & 0.70 & Relisital \\
\hline $\mathrm{FII}$ & 0.568 & 0.361 & FAL10 & 0.825 & 0,0 & Relishal \\
\hline 722 & 0.503 & 0.361 & VALI & 0.823 & 0.70 & Relisital \\
\hline$m$ & 0,513 & 0.301 & VALD & 0,01 & 0.00 & Roticalat \\
\hline p24 & 0.223 & 0.361 & FALI & 0.500 & 0.70 & Rotalat \\
\hline PS & 0.652 & 0,0101 & VALD & 0.836 & 00 & Reliabled \\
\hline pro & 0,71 & 0.061 & VALD & 0.527 & 0,0 & Retiabnt \\
\hline$m$ & 0.579 & 0,0101 & FALII & 0,251 & 0,70 & Rolialat \\
\hline$P A$ & 0.603 & 0,301 & हALD & 0.345 & 0.70 & Relisital \\
\hline 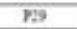 & 0376 & 0301 & VALID & 0327 & 0,70 & Reliaty \\
\hline P30 & 0.820 & 0.361 & र्या & 0.835 & 0.0 & Reliated \\
\hline PHI & 0.820 & 0.361 & जAप्य & 0.325 & 0,0 & Relabial \\
\hline
\end{tabular}

Dari hasil uji validitas dan reliabilitas dengan menggunakan rumusan hitungan pada software SPSS.22 diperoleh hasil melalui uji validitas menggunakan Rumus Korelasi Pearson. Jika rxy $>\mathrm{r}$ tabel maka instrument yang dipakai dapat dikatakan valid. Nilai validitas $\left(\mathrm{r}_{\mathrm{i}}\right)$ lebih besar dari $\mathrm{r}_{\text {tabel }}$ untuk jumlah sampel 30 orang $(n=30, d b=n-2=28), \alpha=0.05$ maka $r_{\text {tabel }}=0.361$ dan $r_{\text {tabel }}<r_{\text {hitung }}(0,361<$

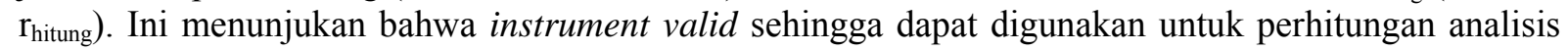
selanjutnya. Perhitungan menggunakan nilai Cronbach Alpha. Menurut Sekaran (1992) reliabilitas < 0.6 adalah kurang baik. Sedangkan reabilitas 0.7 adalah dapat diterima dan reliabilitas 0.8 adalah baik. 
Dari hasil hitung yang di peroleh dengan menggunakan SPSS.22, secara keseluruhan nilai reliabilitas semua instrumentnya adalah lebih besar dari 0.7 , maka dapat dikatakan bahwa semua instrument data tersebut adalah reliabel.

\section{Uji Hipotesis}

Perumusan hipotesiss dalam penelitian ini merupakan langkah ketiga, setelah peneliti mengemukakan landasan teori dan kerangka berpikir. Karena penelitian menggunakan pendekatan kuantitatif, maka dilakukan uji hipotesa, dalam analisis ini penulis menggunakan hipotesa asosiatif (hubungan) untuk mengetahui hubungan antara variabel $5 \mathrm{~K}(\mathrm{X})$ dengan variabel upaya peningkatan produktivitas (Y). Hipotesis yang diuji adalah seperti didalam tabel 4.8

Ho : Terdapat korelasi yang significant antara $\mathrm{X}$ dengan $\mathrm{Y}$

$\mathrm{H}_{1}$ : Tidak terdapat korelasi yang significant antara $\mathrm{X}$ dan $\mathrm{Y}$

$\mathbf{X}=$ Seiri , Seiton, Seiso, Seiketsu, Shitsuke

$\mathrm{Y}=$ Produktivitas

Tabel 4 Nilai korelasi

\begin{tabular}{|l|l|l|}
\hline \multicolumn{2}{|l|}{ Peubah X } & Produktivitas Y \\
\hline \multirow{4}{*}{$\begin{array}{l}\text { Seiri } \\
\text { KETERIBAN }\end{array}$} & nilai korelasi & $-0,028$ \\
\cline { 2 - 3 } & p-value & 0,881 \\
\cline { 2 - 3 } $\begin{array}{l}\text { Seiton } \\
\text { KERAPIHAN }\end{array}$ & nilai korelasi & 30 \\
\hline \multirow{4}{*}{$\begin{array}{l}\text { Seiso } \\
\text { KEBERSIHAN }\end{array}$} & p-value & 0,271 \\
\hline \multirow{4}{*}{$\begin{array}{l}\text { Sitsuke } \\
\text { KELESTARIAN }\end{array}$} & nilai korelasi & 0,140 \\
\hline \multirow{3}{*}{$\begin{array}{l}\text { Seiketsu } \\
\text { KEDISPLINAN }\end{array}$} & p-value & 30 \\
\cline { 2 - 3 } & $\mathbf{n}$ & $\mathbf{0 , 6 5 5} * *$ \\
\hline & nilai korelasi & $\mathbf{0 , 0 0 0}$ \\
\cline { 2 - 3 } & p-value & 0,252 \\
\cline { 2 - 3 } & n & 0,172 \\
\cline { 2 - 3 } & nilai korelasi & $\mathbf{0 , 7 0 7 * *}$ \\
\cline { 2 - 3 } & p-value & $\mathbf{0 , 0 0 0}$ \\
\hline
\end{tabular}

Keterangan : **) significant pada alpha $1 \% \quad *$ ) significant pada alpha 5\%

Hasil perhitungan dari beberapa analisis yang telah dilakukan Maka dapat dikatakan bahwa berdasarkan hasil uji korelasi hubungan antara peubah $\mathrm{X}$ dan $\mathrm{Y}$, yang tidak berpengaruh secara signifikan terhadap produktivitas adalah Seiso/Kebersihan dan Shitsuke/Kedisplinan, sedangkan Seiri/Ketertiban, Seiso/Kerapihan, Seiketsu/Kelestarian, ada berpengaruh yang signifikan. Respon SDM terhadap implementasi 5K2S cukup signifikan hal ini di buktikan dengan hasil respon kuesioner yang jatuh pada nilai level rata-rata jawaban pada $82.24 \%$ atau nilai point 4,11 (yaitu antara Setuju (S) dan Sangat Setuju (ST).

Dari hasil analisis dan keterkaitan pengaruh implementasi 5K2S pada upaya peningkatan produktivitas, maka kondisi pada sumber daya manusia dan tempat kerja karyawan PT. Andesen Jaya Plastik divisi produksi seluruh karyawan telah merespon terhadap implementasi $5 \mathrm{~K} 2 \mathrm{~S}$ yang mencapaian $82,24 \%$. Hal ini berarti tahapan yang telah dicapai baru pada tahapan kedua, yaitu tahap pembudayaan. 


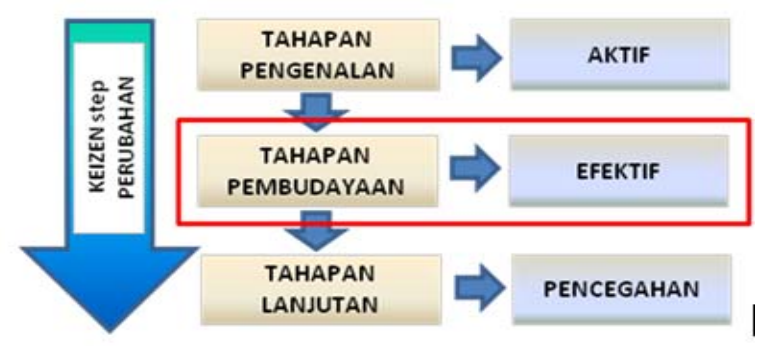

Gambar 3 Tingkatan Kaizen

Tahapan yang telah dicapai perlu di tingkatkan pada tahap berikutnya yaitu tahap lanjutan atau pencegahan. Pemberian reward dan punishment dari hasil pelaksanaan $5 \mathrm{~K} 2 \mathrm{~S}$ bagi yang berhasil ataupun yang belum, yang langsung mendapat perhatian manajemen puncak. Memaksimalkan seluruh karyawan untuk memahami pengetahuan tentang $5 \mathrm{~K} 2 \mathrm{~S}$ secara total, melalui training dan pelatihan secara masif. Penjadwalan 5K2S yang jelas perlu dilakukan dan dipahami oleh seluruh karyawan. Memberikan insentif kehadiran agar menjadikan motivasi bagi karyawan yang sering terlambat. Menggencarkan aktivitas pemahaman budaya Kaizen yaitu dengan melaksanakan continuous improvement (GKM) melalui small activity.

Mengimplementasikan tools manajemen lain untuk peningkatan produktivitas, seperti Total Produktivity Maintenance (TPM), Just In Time (JIT), Suggestion System (Sumbang Saran), dan sebagainya. Sedangkan hal-hal lainnya yang mengacu kepada sistem adalah perlunya dukungan top management yang tidak boleh surut dan menjadi cotoh keteladanan seluruh karyawan. Dampaknya terhadap upaya peningkatan produktivitas dapat dicerminkan dari kenaikan rata-rata produksi hingga $8 \%$ sementara data kegagalan proses turun dan mencapai dibawah 5\% pada bulan Oktober 2014, hal tersebut sesuai keinginan dan target manajemen.

Tabel 5 data produksi $2011 \sim$ Okt. 2014

\begin{tabular}{|c|c|c|c|c|c|c|c|c|c|}
\hline \multirow{3}{*}{ No, } & \multirow{3}{*}{$\begin{array}{l}\text { Kode } \\
\text { Produk }\end{array}$} & \multicolumn{8}{|c|}{ HASIL PENJUALAN PRODUK UNTUK 4 TAHUN TERAKHIR } \\
\hline & & \multicolumn{2}{|c|}{2011} & \multicolumn{2}{|c|}{2012} & \multicolumn{2}{|c|}{2013} & \multicolumn{2}{|c|}{2014 (Okt) } \\
\hline & & Good & NG & Good & NG & Good & NG & Good & NG \\
\hline 1 & $\mathrm{~B}-03 \mathrm{~A} 5$ & 45246 & 4071 & 5889 & 510 & 8656 & 675 & 8600 & 430 \\
\hline 2 & $\mathrm{~B}-03 \mathrm{~A} 1$ & 18516 & 1660 & 24470 & 2220 & 35971 & 2800 & 34560 & 1720 \\
\hline 3 & W-05A3 & 103866 & 9347 & 137105 & 12400 & 201544 & 14670 & 201690 & 10020 \\
\hline 4 & W-06A3 & 128364 & 11550 & 169445 & 14398 & 249080 & 19200 & 233988 & 11511 \\
\hline 5 & W-07A3 & 169176 & 15225 & 223312 & 20280 & 328269 & 23500 & 321097 & 15901 \\
\hline 6 & W-06A9 & 86322 & 7768 & 113952 & 10358 & 167551 & 12990 & 164300 & 8111 \\
\hline 7 & W-06A5 & 114498 & 10308 & 151130 & 13753 & 222165 & 16300 & 224378 & 11200 \\
\hline 8 & W-04A5 & 89508 & 8011 & 118150 & 10750 & 173680 & 13490 & 171048 & 8551 \\
\hline \multicolumn{2}{|c|}{ Total } & (755496 & 67940 & 943453 & 84669 & 1386916 & 103625 & 1359661 & 67444 \\
\hline \multicolumn{2}{|c|}{ Reject } & \multicolumn{2}{|c|}{$8.99 \%$} & \multicolumn{2}{|c|}{$8.97 \%$} & \multicolumn{2}{|c|}{$7.47 \%$} & \multicolumn{2}{|c|}{$4.96 \%$} \\
\hline \multicolumn{2}{|c|}{ Kenaikan } & & & \multicolumn{2}{|c|}{$20 \%$} & \multicolumn{2}{|c|}{$32 \%$} & \multicolumn{2}{|c|}{$18 \%$} \\
\hline
\end{tabular}

Sumber: data bagian produksi 
Grafik Data Produksi 2011 OKT. 2014

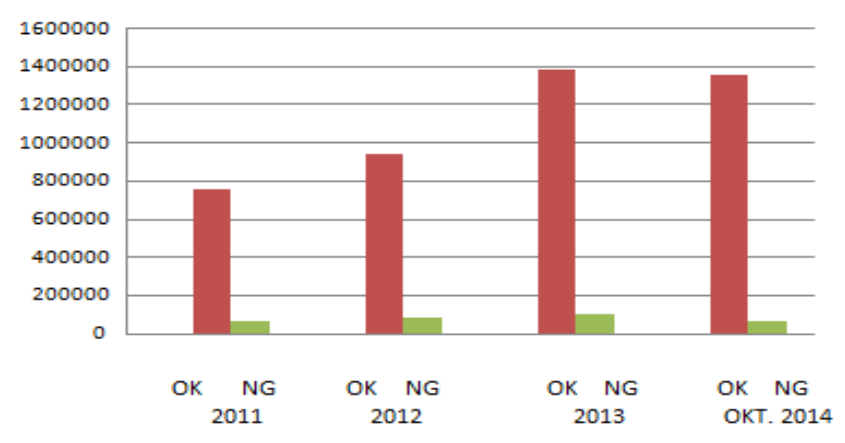

Gambar 4 Grafik Data

\section{SIMPULAN}

Dari hasil hipotesis diketahui bahwa terdapat korelasi yang signifikan dari K1 (Ketertiban), K2 (Kerapihan), dan K4 (Kelestarian) pada upaya peningkatan produktivitas. Hal tersebut dapat dilihat dari budaya jum'at bersih selama 30 menit yang sudah dilaksanakan selama ini. Untuk K3 (Kebersihan) dan K5 (Kedisiplinan), sesuai hasil perhitungan tidak ada korelasi yang signifikan terhadap upaya peningkatan produktivitas karena ada beberapa pengaruh eksternal yang terkadang muncul di luar dugaan. Pengaruh eksternal yang di luar dugaan tersebut seperti, lingkungan dalam proses finishing sehingga menghasilkan serpihan sampah kikiran, kemacetan lalu lintas (karyawan masuk terlambat) dan lainnya. Selain itu pemahaman $5 \mathrm{~K} 2 \mathrm{~S}$ belum merata, perilaku Etis karyawan seperti senioritas, kesukuan, Ras, agama dan lainnya, kemudian Responden dalam penelitian ini hanya di fokuskan terhadap karyawan produksi, sedangkan divisi maintenance, HRD, Gudang, dan lainnya, belum di analisis.

Manajemen atau pimpinan perusahaan dapat membuat strategi untuk dapat memaksimalkan seluruh karyawan dalam memahami pengetahuan tentang $5 \mathrm{~K} 2 \mathrm{~S}$ secara total, melalui training dan pelatihan secara masif. Jadwal $5 \mathrm{~K} 2 \mathrm{~S}$ yang jelas perlu ada dan dipahami oleh seluruh karyawan. Pemberian insentif juga dapat dilakukan untuk kehadiran karyawan agar menjadikan motivasi bagi karyawan yang sering terlambat.

Untuk mendukung hal-hal tersebut aktivitas continuous improvement dapat dilakukan melalui small activity, dan mengimplementasikan tools manajemen lainnya untuk peningkatan produktivitas, seperti Total Preventive Maintenance (TPM), Just In Time (JIT), Suggestion System (Sumbang Saran), dan sebagainya. Sedangkan hal-hal lain yang mengacu kepada sistem perlu didukung oleh top manajemen perusahaan untuk menjadi contoh keteladanan bagi seluruh karyawan. 


\section{DAFTAR PUSTAKA}

Arikunto, Suharsimi. 2006. Prosedur Penelitian Suatu Pendekatan Praktik. Jakarta : Rineka Cipta

Cho, F. (2001). Toyota Way document. Japan: Toyota

Hirano, H. (2002). Penerapan $5 S$ di tempat kerja, Pendekatan langkah-langkah Praktis. Jakarta: PQM.

Mulyadi. (1998). Total Quality Mangement. Jakarta: Aditya Media.

Sarwono, J., Martadiredja, T. (2008). Riset Bisnis untuk Pengambilan Keputusan. Yogyakarta: ANDI.

Sarwono. J. (2006). Metode Penelitian Kuantitatif dan Kualitatif. Yogyakarta: Penerbit Graha Ilmu.

Sekaran, U. (1992), Research Method for Business A Skill Building Approach. John Wiley and Sons, Inc. New York.

Sugiyono. (2002). Metodologi Penelitian Kombinasi. Bandung: Alfabeta.

Umar, Husein. (2000). Metodologi Penelitian. Jakarta: PT. Gramedia Pustaka Utama.

Y. Wibisono. (2009). Metode Statistik. UGM Yogyakarta: Gajah Mada University Press. 


\section{LAMPIRAN}

\begin{tabular}{|c|c|c|c|c|c|c|c|}
\hline \multicolumn{8}{|c|}{ Correlations } \\
\hline & & P1 & P2 & P3 & P4 & P5 & Seiri \\
\hline \multirow[t]{3}{*}{$\mathrm{P} 1$} & Pearson Correlation & 1 &,- 004 & ,232 & ,270 & ,025 &, $434^{*}$ \\
\hline & Sig. (2-tailed) & & ,985 & ,208 & ,142 & 894 & 015 \\
\hline & $\mathrm{N}$ & 31 & 31 & 31 & 31 & 31 & 31 \\
\hline \multirow[t]{3}{*}{$\mathrm{P} 2$} & Pearson Correlation &,- 004 & 1 & ,144 & ,086 & ,068 &, $660^{* *}$ \\
\hline & Sig. (2-tailed) & ,985 & & ,439 & ,645 & ,715 &, 000 \\
\hline & $\mathrm{N}$ & 31 & 31 & 31 & 31 & 31 & 31 \\
\hline \multirow[t]{3}{*}{$\mathrm{P3}$} & Pearson Correlation & 232 & ,144 & 1 & ,261 &,- 148 &, $444^{*}$ \\
\hline & Sig. (2-tailed) & ,208 & ,439 & & ,156 &, 427 & ,012 \\
\hline & $\mathrm{N}$ & 31 & 31 & 31 & 31 & 31 & 31 \\
\hline \multirow[t]{3}{*}{ P4 } & Pearson Correlation & ,270 & ,086 & ,261 & 1 & ,212 &, $598^{\star \star}$ \\
\hline & Sig. (2-tailed) & ,142 & ,645 & ,156 & & ,252 & ,000 \\
\hline & $\mathrm{N}$ & 31 & 31 & 31 & 31 & 31 & 31 \\
\hline \multirow[t]{3}{*}{ P5 } & Pearson Correlation & ,025 & ,068 &,- 148 & ,212 & 1 & $478^{* *}$ \\
\hline & Sig. (2-tailed) & ,894 & ,715 &, 427 & ,252 & & ,006 \\
\hline & $\mathrm{N}$ & 31 & 31 & 31 & 31 & 31 & 31 \\
\hline \multirow[t]{3}{*}{ Seiri } & Pearson Correlation &, $434^{\star}$ &, $660^{\star \star}$ & ,444* &, $598^{\star \star}$ &, $478^{\star \star}$ & 1 \\
\hline & Sig. (2-tailed) & ,015 &, 000 & ,012 &, 000 & ,006 & \\
\hline & $\mathrm{N}$ & 31 & 31 & 31 & 31 & 31 & 31 \\
\hline
\end{tabular}

*. Correlation is significant at the 0.05 level (2-tailed).

**. Correlation is significant at the 0.01 level (2-tailed)

Correlations

\begin{tabular}{|c|c|c|c|c|c|c|c|}
\hline & & P6 & P7 & P8 & P9 & P10 & Seiton \\
\hline \multirow[t]{3}{*}{$\overline{P 6}$} & Pearson Correlation & 1 & ,032 & ,266 & ,283 &, $402^{\star}$ &, $630^{\star \star}$ \\
\hline & Sig. (2-tailed) & & ,865 & 148 & ,122 &, 025 &, 000 \\
\hline & $\mathrm{N}$ & 31 & 31 & 31 & 31 & 31 & 31 \\
\hline \multirow[t]{3}{*}{ P7 } & Pearson Correlation & ,032 & 1 & ,216 & ,055 &,- 226 & ,389* \\
\hline & Sig. (2-tailed) & ,865 & & ,243 & ,770 & ,222 &, 030 \\
\hline & $\mathrm{N}$ & 31 & 31 & 31 & 31 & 31 & 31 \\
\hline \multirow[t]{3}{*}{ P8 } & Pearson Correlation & ,266 & ,216 & 1 &, $374^{*}$ & ,351 &, $738^{\star *}$ \\
\hline & Sig. (2-tailed) & 148 & ,243 & & ,038 & ,053 &, 000 \\
\hline & $\mathrm{N}$ & 31 & 31 & 31 & 31 & 31 & 31 \\
\hline \multirow[t]{3}{*}{ P9 } & Pearson Correlation & ,283 & ,055 & ,374* & 1 &,- 023 &, $655^{\star *}$ \\
\hline & Sig. (2-tailed) & 122 &, 770 & ,038 & & ,902 &, 000 \\
\hline & $\mathrm{N}$ & 31 & 31 & 31 & 31 & 31 & 31 \\
\hline \multirow[t]{3}{*}{ P10 } & Pearson Correlation & ,402* &,- 226 & ,351 &,- 023 & 1 &, $476^{\star \star}$ \\
\hline & Sig. (2-tailed) & 025 & ,222 & ,053 & ,902 & & ,007 \\
\hline & $\mathrm{N}$ & 31 & 31 & 31 & 31 & 31 & 31 \\
\hline \multirow[t]{3}{*}{ Seiton } & Pearson Correlation &, $630^{\star \star}$ & ,389* &, $738^{\star \star}$ & ,655** &, $476^{\star \star}$ & 1 \\
\hline & Sig. (2-tailed) &, 000 & 030 &, 000 & ,000 &, 007 & \\
\hline & $\mathrm{N}$ & 31 & 31 & 31 & 31 & 31 & 31 \\
\hline
\end{tabular}

*. Correlation is significant at the 0.05 level (2-tailed).

**. Correlation is significant at the 0.01 level (2-tailed). 
Correlations

\begin{tabular}{|c|c|c|c|c|c|c|c|}
\hline & & P11 & P12 & P13 & $\mathrm{P} 14$ & P15 & Seiso \\
\hline \multirow[t]{3}{*}{ P11 } & Pearson Correlation & 1 &,- 031 &, 019 &, 072 &, $527^{\star \star}$ &, $599^{\star \star}$ \\
\hline & Sig. (2-tailed) & & ,867 & ,918 & ,699 & ,002 & ,000 \\
\hline & $\mathrm{N}$ & 31 & 31 & 31 & 31 & 31 & 31 \\
\hline \multirow[t]{3}{*}{ P12 } & Pearson Correlation &,- 031 & 1 &, $530 * *$ & ,165 & ,450* &, $618^{\star \star}$ \\
\hline & Sig. (2-tailed) & ,867 & & ,002 & ,374 & ,011 & ,000 \\
\hline & $\mathrm{N}$ & 31 & 31 & 31 & 31 & 31 & 31 \\
\hline \multirow[t]{3}{*}{ P13 } & Pearson Correlation & ,019 &, $530 \star \star$ & 1 &,- 014 & ,124 &, $458^{\star \star}$ \\
\hline & Sig. (2-tailed) & ,918 & ,002 & & ,940 &, 505 & ,010 \\
\hline & $\mathrm{N}$ & 31 & 31 & 31 & 31 & 31 & 31 \\
\hline \multirow[t]{3}{*}{ P14 } & Pearson Correlation & ,072 & , 165 &,- 014 & 1 & ,367* &, $537^{\star \star}$ \\
\hline & Sig. (2-tailed) & ,699 & ,374 & ,940 & & ,042 & ,002 \\
\hline & $\mathrm{N}$ & 31 & 31 & 31 & 31 & 31 & 31 \\
\hline \multirow[t]{3}{*}{ P15 } & Pearson Correlation &, $527^{* \star}$ & $450^{*}$ & ,124 & ,367* & 1 & $835^{\star \star}$ \\
\hline & Sig. (2-tailed) & ,002 & ,011 &, 505 & ,042 & & ,000 \\
\hline & $\mathrm{N}$ & 31 & 31 & 31 & 31 & 31 & 31 \\
\hline \multirow[t]{3}{*}{ Seiso } & Pearson Correlation &, $599 * \star$ & ,618** &, $458^{* *}$ &, $537 * \star$ & ,835** & 1 \\
\hline & Sig. (2-tailed) & ,000 & ,000 & ,010 & ,002 &, 000 & \\
\hline & $\mathrm{N}$ & 31 & 31 & 31 & 31 & 31 & 31 \\
\hline
\end{tabular}

**. Correlation is significant at the 0.01 level (2-tailed).

*. Correlation is significant at the 0.05 level (2-tailed).

Correlations

\begin{tabular}{|c|c|c|c|c|c|c|c|}
\hline & & P16 & P17 & P18 & P19 & P20 & Sitsuke \\
\hline \multirow[t]{3}{*}{ P16 } & Pearson Correlation & 1 & ,112 &, $394^{\star}$ & ,230 &, $414^{*}$ &, $610^{\star \star}$ \\
\hline & Sig. (2-tailed) & & ,548 & ,029 & ,213 & ,021 &, 000 \\
\hline & $\mathrm{N}$ & 31 & 31 & 31 & 31 & 31 & 31 \\
\hline \multirow[t]{3}{*}{ P17 } & Pearson Correlation & ,112 & 1 & ,186 &, $568^{\star \star}$ & ,300 &, $665^{\star \star}$ \\
\hline & Sig. (2-tailed) &, 548 & & ,316 & ,001 & 101 & ,000 \\
\hline & $\mathrm{N}$ & 31 & 31 & 31 & 31 & 31 & 31 \\
\hline \multirow[t]{3}{*}{ P18 } & Pearson Correlation & ,394* & ,186 & 1 & ,342 & ,009 &, $726^{\star \star}$ \\
\hline & Sig. (2-tailed) & ,029 & ,316 & & ,059 & ,960 & ,000 \\
\hline & $\mathrm{N}$ & 31 & 31 & 31 & 31 & 31 & 31 \\
\hline \multirow[t]{3}{*}{ P19 } & Pearson Correlation & ,230 & ,568*夫 & ,342 & 1 & ,015 & ,694** \\
\hline & Sig. (2-tailed) & ,213 & ,001 & ,059 & & ,937 & ,000 \\
\hline & $\mathrm{N}$ & 31 & 31 & 31 & 31 & 31 & 31 \\
\hline \multirow[t]{3}{*}{$\mathrm{P} 20$} & Pearson Correlation &, $414^{\star}$ & 300 & ,009 & ,015 & 1 &, $436^{*}$ \\
\hline & Sig. (2-tailed) & ,021 & ,101 & ,960 & ,937 & &, 014 \\
\hline & $\mathrm{N}$ & 31 & 31 & 31 & 31 & 31 & 31 \\
\hline \multirow[t]{3}{*}{ Sitsuke } & Pearson Correlation & ,610** &, $665^{\star \star}$ &, $726^{\star \star}$ & ,694** &, $436^{\star}$ & 1 \\
\hline & Sig. (2-tailed) &, 000 &, 000 &, 000 &, 000 &, 014 & \\
\hline & $\mathrm{N}$ & 31 & 31 & 31 & 31 & 31 & 31 \\
\hline
\end{tabular}

*. Correlation is significant at the 0.05 level (2-tailed).

**. Correlation is significant at the 0.01 level (2-tailed). 
Correlations

\begin{tabular}{|c|c|c|c|c|c|c|c|}
\hline & & P21 & $\mathrm{P} 22$ & P23 & P24 & $\mathrm{P} 25$ & Seiketsu \\
\hline \multirow[t]{3}{*}{$\overline{\mathrm{P} 21}$} & Pearson Correlation & 1 & ,123 &, $435^{\star}$ &, $854^{\star \star}$ &, $493^{\star \star}$ &, $868^{\star \star}$ \\
\hline & Sig. (2-tailed) & & ,511 & ,015 & ,000 & ,005 & ,000 \\
\hline & $\mathrm{N}$ & 31 & 31 & 31 & 31 & 31 & 31 \\
\hline \multirow[t]{3}{*}{$\mathrm{P} 22$} & Pearson Correlation & ,123 & 1 & ,106 & ,123 & ,320 &, $503^{\star \star}$ \\
\hline & Sig. (2-tailed) &, 511 & &, 570 & ,511 & ,080 & ,004 \\
\hline & $\mathrm{N}$ & 31 & 31 & 31 & 31 & 31 & 31 \\
\hline \multirow[t]{3}{*}{$\mathrm{P} 23$} & Pearson Correlation &, $435^{\star}$ & ,106 & 1 & ,270 &,- 069 &, $513^{\star \star}$ \\
\hline & Sig. (2-tailed) & ,015 & ,570 & & ,141 & ,711 & ,003 \\
\hline & $\mathrm{N}$ & 31 & 31 & 31 & 31 & 31 & 31 \\
\hline \multirow[t]{3}{*}{ P24 } & Pearson Correlation & $854 *$ & ,123 & ,270 & 1 & $4993^{\star \star}$ &, $823^{\star *}$ \\
\hline & Sig. (2-tailed) & ,000 &, 511 & 141 & & ,005 &, 000 \\
\hline & $\mathrm{N}$ & 31 & 31 & 31 & 31 & 31 & 31 \\
\hline \multirow[t]{3}{*}{ P25 } & Pearson Correlation & ,493** & ,320 &,- 069 &, $493^{\star \star}$ & 1 &, $652^{\star \star}$ \\
\hline & Sig. (2-tailed) & ,005 & ,080 & ,711 & ,005 & & ,000 \\
\hline & $\mathrm{N}$ & 31 & 31 & 31 & 31 & 31 & 31 \\
\hline \multirow[t]{3}{*}{ Seiketsu } & Pearson Correlation & ,868** &, $503^{\star \star}$ &, $513^{\star \star}$ & ,823** &, $652^{\star \star}$ & 1 \\
\hline & Sig. (2-tailed) & ,000 & ,004 & ,003 & ,000 & ,000 & \\
\hline & $\mathrm{N}$ & 31 & 31 & 31 & 31 & 31 & 31 \\
\hline
\end{tabular}

*. Correlation is significant at the 0.05 level (2-tailed).

**. Correlation is significant at the 0.01 level (2-tailed).

\begin{tabular}{|c|c|c|c|c|c|c|c|}
\hline \multicolumn{8}{|c|}{ Correlations } \\
\hline & & P26 & P27 & P28 & P29 & P30 & Produktivitas \\
\hline \multirow[t]{3}{*}{ P26 } & Pearson Correlation & 1 &, $382^{\star}$ & ,214 &, $815^{\star \star}$ &, $539^{\star \star *}$ &, $751^{\star \star}$ \\
\hline & Sig. (2-tailed) & & ,034 & 247 &, 000 & ,002 & ,000 \\
\hline & $\mathrm{N}$ & 31 & 31 & 31 & 31 & 31 & 31 \\
\hline \multirow[t]{3}{*}{$\mathrm{P} 27$} & Pearson Correlation & ,382* & 1 &,- 081 &, $527^{\star \star}$ &, $450^{\star}$ &, 579 ** \\
\hline & Sig. (2-tailed) & ,034 & & ,663 &, 002 &, 011 & ,001 \\
\hline & $\mathrm{N}$ & 31 & 31 & 31 & 31 & 31 & 31 \\
\hline \multirow[t]{3}{*}{$\mathrm{P} 28$} & Pearson Correlation & ,214 &,- 081 & 1 & ,315 & ,355* &, $603^{\star \star}$ \\
\hline & Sig. (2-tailed) & ,247 & ,663 & & ,084 & ,050 & ,000 \\
\hline & $\mathrm{N}$ & 31 & 31 & 31 & 31 & 31 & 31 \\
\hline \multirow[t]{3}{*}{$\mathrm{P} 29$} & Pearson Correlation &, $815^{\star \star}$ &, $527^{\star \star}$ & ,315 & 1 &, $697^{* *}$ & $876^{\star \star *}$ \\
\hline & Sig. (2-tailed) &, 000 & ,002 & ,084 & &, 000 &, 000 \\
\hline & $\mathrm{N}$ & 31 & 31 & 31 & 31 & 31 & 31 \\
\hline \multirow[t]{3}{*}{ P30 } & Pearson Correlation &, $539 * \star$ &, $450^{\star}$ & ,355* & ,697** & 1 &, $820^{\star \star}$ \\
\hline & Sig. (2-tailed) & ,002 & 011 &, 050 & ,000 & & ,000 \\
\hline & $\mathrm{N}$ & 31 & 31 & 31 & 31 & 31 & 31 \\
\hline \multirow[t]{3}{*}{ Produktivitas } & Pearson Correlation & ,751** &, $579 \star \star$ &, $603^{* \star}$ & $876^{* \star}$ & $820 * *$ & 1 \\
\hline & Sig. (2-tailed) &, 000 & ,001 & ,000 & ,000 & ,000 & \\
\hline & $\mathrm{N}$ & 31 & 31 & 31 & 31 & 31 & 31 \\
\hline
\end{tabular}

*. Correlation is significant at the 0.05 level (2-tailed).

**. Correlation is significant at the 0.01 level (2-tailed).

\section{Scale Statistics}

\begin{tabular}{|c|r|r|r|}
\hline Mean & Variance & Std. Deviation & N of Items \\
\hline 123,5161 & 60,591 & 7,78405 & 30 \\
\hline
\end{tabular}




\section{Correlations}

Correlations

\begin{tabular}{|c|c|c|c|c|c|c|c|}
\hline & & Seiri & Seiton & Seiso & Sitsuke & Seiketsu & Produktivitas \\
\hline \multirow[t]{3}{*}{ Seiri } & Pearson Correlation & 1 &, 232 &, 236 &, 325 &,- 011 &,- 028 \\
\hline & Sig. (2-tailed) & & 209 & ,200 & 075 & ,953 & ,881 \\
\hline & $\mathrm{N}$ & 31 & 31 & 31 & 31 & 31 & 31 \\
\hline \multirow[t]{3}{*}{ Seiton } & Pearson Correlation & ,232 & 1 &, $535^{\star \star}$ & ,601** &, $450^{*}$ & ,271 \\
\hline & Sig. (2-tailed) & 209 & & ,002 &, 000 & ,011 & 140 \\
\hline & $\mathrm{N}$ & 31 & 31 & 31 & 31 & 31 & 31 \\
\hline \multirow[t]{3}{*}{ Seiso } & Pearson Correlation & ,236 & ,535** & 1 & ,508*夫 & ,719** & $655^{\star \star}$ \\
\hline & Sig. (2-tailed) & ,200 & ,002 & &, 004 &, 000 & ,000 \\
\hline & $\mathrm{N}$ & 31 & 31 & 31 & 31 & 31 & 31 \\
\hline \multirow[t]{3}{*}{ Sitsuke } & Pearson Correlation & ,325 &, $601^{* *}$ &, $508^{\star \star *}$ & 1 & ,331 & ,252 \\
\hline & Sig. (2-tailed) & 075 & ,000 &, 004 & & ,069 & ,172 \\
\hline & $\mathrm{N}$ & 31 & 31 & 31 & 31 & 31 & 31 \\
\hline \multirow[t]{3}{*}{ Seiketsu } & Pearson Correlation &,- 011 &, $450 *$ & ,719** & ,331 & 1 &, $707^{\star \star}$ \\
\hline & Sig. (2-tailed) & ,953 & ,011 &, 000 & ,069 & & ,000 \\
\hline & $\mathrm{N}$ & 31 & 31 & 31 & 31 & 31 & 31 \\
\hline \multirow[t]{3}{*}{ Produktivitas } & Pearson Correlation &,- 028 & ,271 &, $655^{\star \star *}$ & ,252 &, $707^{\star \star}$ & 1 \\
\hline & Sig. (2-tailed) & ,881 & ,140 &, 000 & ,172 & ,000 & \\
\hline & $\mathrm{N}$ & 31 & 31 & 31 & 31 & 31 & 31 \\
\hline
\end{tabular}

